\title{
Molecular analysis of the macrolide-lincosamide resistance gene region of a novel plasmid from Staphylococcus hyicus
}

\author{
S. SCHWARZ, CARLA LANGE and CHRISTIANE WERCKENTHIN
}

Institut für Kleintierforschung Celle/Merbitz der Bundesforschungsanstalt für Landwirtschaft BraunschweigVölkenrode (FAL), 29223 Celle, Germany

\begin{abstract}
Resistance to macrolides and lincosamides in Staphylococcus hyicus has been shown to be encoded by a 4.0-kb plasmid designated pSES21. It differed distinctly in its restriction map from all other staphylococcal macrolide resistance plasmids reported so far. Southern blot hybridisation with gene probes specific for staphylococcal erm genes demonstrated that the macrolide resistance gene belonged to hybridisation class $C$. Analysis of the erm $\mathrm{C}$ gene revealed that the deduced amino-acid sequence of the pSES21-encoded ErmC methylase exhibited c. $93 \%$ identity with the ErmC methylase encoded by plasmid pE194. The ermC gene of pSES21 was expressed constitutively and sequence analysis of the regulatory region showed multiple base-pair insertions and substitutions in the translational attenuator. As a consequence of these mutations, the reading frame of the small regulatory peptide was destroyed and a novel pair of inverted repeated sequences was generated. Previous studies identified sequence deletions and sequence duplications in the erm $\mathrm{C}$ regulatory region as the basis for constitutive erm $\mathrm{C}$ gene expression. The multiple point mutations shown in the pSES21-encoded ermC translational attenuator represent a novel kind of structural alteration in this regulatory region and may explain constitutive erm $\mathrm{C}$ gene expression by pairing of the newly generated inverted repeated segments in the presence of a functionally deleted reading frame for the small regulatory peptide.
\end{abstract}

\section{Introduction}

Staphylococcal resistance to macrolide-lincosamidestreptogramin B (MLS) antibiotics is commonly mediated by the genes $\operatorname{erm} \mathrm{A}$, erm $\mathrm{B}$ or $\operatorname{erm} \mathrm{C}[1,2]$. While the transposon-encoded genes erm $\mathrm{A}$ and erm $\mathrm{B}$ have rarely been detected in staphylococci, the plasmid-encoded gene erm $\mathrm{C}$ is the predominant MLS resistance gene in staphylococcal isolates from both man and animals [3]. The erm $\mathrm{C}$ gene has been found on small plasmids of $2.3-4.0 \mathrm{~kb}[1,4-16]$. Two different types of plasmids have been described so far, between which homology has been limited to the erm $\mathrm{C}$ region. The $3.7-\mathrm{kb}$ plasmid $\mathrm{pE} 194$ from Staphylococcus aureus [7] represents one type of erm C plasmid, the 2.35-kb plasmid pNE131 from $S$. epidermidis [8] the other type. Expression of the erm $\mathrm{C}$

Received 30 Jan 1997; accepted 8 May 1997. Corresponding author: Dr S. Schwarz. gene has been found to be either inducible by 14- and 15-membered macrolides or constitutive $[17,18]$. The genetic basis for the differences of both types of erm $\mathrm{C}$ gene expression is in the erm $\mathrm{C}$ regulatory region, which is located immediately upstream of the erm C structural gene. The regulatory region of inducible erm $\mathrm{C}$ genes is referred to as the translational attenuator and comprises two pairs of inverted repeated sequences as well as a small open reading frame for a regulatory peptide [7, 8, 19-21]. Changes from the inducible to the constitutive type of erm $\mathrm{C}$ gene expression involve structural alterations in the translational attenuator. So far, two types of structural changes have been reported: (i) sequence deletions of varying extent $[4,8,10,22]$ and (ii) sequence duplications at different locations in the translational attenuator $[9,12,23]$.

This study identified a novel erm C-encoding MLSresistance plasmid, designated pSES21, from S. hyicus and describes its erm $\mathrm{C}$ structural gene and the regulatory region. 


\section{Materials and methods}

Bacterial strains and determination of macrolidelincosamide resistance

The strain of $S$. hyicus was isolated from the skin swab of a tylosin-fed pig and identified by the ID32 STAPH system (bioMérieux, La Balme les Grottes, France). Resistance to macrolide-lincosamide antibiotics was determined by the agar diffusion test [24] with disks (Becton-Dickinson, Heidelberg, Germany) containing erythromycin $15 \mu \mathrm{g}$, lincomycin $10 \mu \mathrm{g}$, or clindamycin $10 \mu \mathrm{g}$ or tablets (Hiss Diagnostics, Freiburg, Germany) containing azithromycin $30 \mu \mathrm{g}$, spiramycin $200 \mu \mathrm{g}$ or tylosin $150 \mu \mathrm{g}$. $S$. aureus RN4220 served as the recipient for plasmid pSES21 in protoplast transformation experiments [25]. During the further course of the study, the original $S$. hyicus strain, as well as $S$. aureus RN4220:pSES21 were grown on sheep blood agar (Oxoid) supplemented with erythromycin $30 \mathrm{mg} / \mathrm{L}$. S. aureus RN4220 carrying plasmid pSES5, which encodes the inducible erm $\mathrm{C}$ gene [11], served as control for the determination of the type of erm C gene expression.

\section{Plasmid analysis and Southern blot hybridisation}

The single plasmid found in the original S. hyicus isolate was transformed into S. aureus RN4220 by polyethylene glycol-mediated protoplast transformation $[25,26] ; S$. aureus RN4220:pSES21 transformants were subsequently selected on DM3 regeneration plates [26] supplemented with erythromycin $30 \mathrm{mg} / \mathrm{L}$. The plasmid, designated pSES21, was isolated by affinity chromatography [27] (Qiagen Midi System, Hilden, Germany) and subjected to restriction endonuclease digests (Boehringer Mannheim, Germany). Uncleaved plasmid pSES21 as well as its restriction fragments were separated in agarose $1-1.5 \% \mathrm{w} / \mathrm{v}$ gels with $1 \times \mathrm{TAE}$ buffer as running buffer. The sizes of the fragments were calculated from logarithmic plots by comparison with the $1-\mathrm{kb}$ ladder (Gibco-BRL, Eggenstein, Germany). To determine the class of erm gene, hybridisation experiments were conducted with the following gene probes: the 472-bp Hae III/HincII internal fragment of the erm C gene of plasmid $\mathrm{pE} 194$ served as erm $\mathrm{C}$ gene probe [7]; the 1.46-kb Cla I fragment of plasmid pSES20 as erm $\mathrm{B}$ gene probe [28]; and the 1.21-kb Cla $\mathrm{I}-E c o \mathrm{RV}$ fragment of transposon Tn554 as ermA probe [29]. Plasmid DNA was transferred from agarose gels to nitrocellulose membranes by the capillary blot procedure [27]. The probes were labelled with the non-radioactive enhanced chemiluminescence system (ECL, Amersham-Buchler, Braunschweig, Germany). High stringency hybridisation conditions were as previously described [27] and the signal was detected with the detection reagents supplied with the ECL kit.

\section{Cloning and sequence analysis}

Plasmid pSES21 was linearised by digestion with the restriction endonucleases EcoRI, XbaI, Bam HI, $H p a \mathrm{II}$, HindIII and HaeIII. The entire linearised plasmids were cloned into pBluescript II SK+ (Stratagene, Heidelberg, Germany) and the recombinant plasmids were transformed into Escherichia coli JM107 [30, 31]. To localise the position of the pSES21-encoded erm gene by its functional inactivation, the transformants were grown overnight at $37^{\circ} \mathrm{C}$ in nutrient agar supplemented with erythromycin $150 \mathrm{mg} / \mathrm{L}$.

Plasmid pBluescript II SK+, which carried the HindIII-linearised pSES21, was chosen for sequence analysis. Initial sequence analyses were performed with the commercially available M13 universal and T3 primers (Stratagene). For additional sequence analyses, four 14-18-mer primers derived from the sequence data obtained were used. Sequence analyses were performed on both strands by the dideoxy chain termination method [32] with the Sequenase 2.0 kit and $\left[\alpha^{32} \mathrm{~S}\right] \mathrm{dATP}$ or by automated nonradioactive sequencing with the AutoRead ${ }^{\mathrm{TM}}$ sequencing kit (Pharmacia) and the ALF DNA analysis system (Pharmacia). The calculation of mRNA stabilities followed the recommendations of Tinoco et al. [33]. Dice coefficients of similarity [34] were calculated to compare the deduced amino-acid sequences of the ErmC methylases encoded by the plasmids pE194 [7], pIM13 [22], pT48 [5], pNE131 [8], pSES4a [11], pSES5 [11], pSES6 [9, 11] and pSES21.

\section{Nucleotide sequence accession number}

The nucleotide sequence of the pSES21-encoded erm C gene and its regulatory region has been submitted to the EMBL database and assigned accession number Y09003.

\section{Results}

Analysis of the pSES21-encoded ermC gene

The 4.0-kb plasmid pSES21 from $S$. hyicus was shown by protoplast transformation to mediate macrolidelincosamide resistance. Hybridisation with specific gene probes for staphylococcal erm genes demonstrated that the pSES21-encoded erm gene belonged to the hybridisation class C. Although pSES21 resembled the MLS resistance plasmids pE194 and pSES6 in size, restriction mapping did not reveal homology of pSES21 to either of the two types of erm $\mathrm{C}$ plasmids, so far described in staphylococci (Fig. 1). Particularly, the characteristic arrangement of SacI, Hae III, BclI and $\mathrm{Cla} \mathrm{I}$ sites within the $\mathrm{erm} \mathrm{C}$ gene region was missing in pSES21. 
pE194

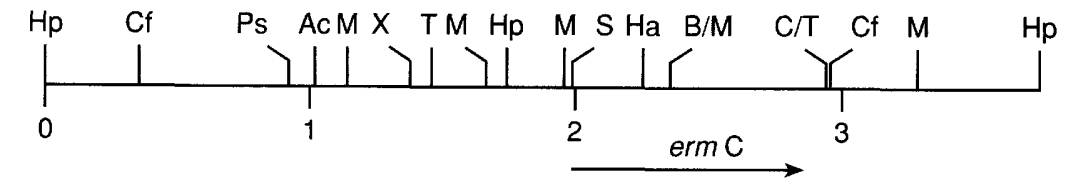

pSES6

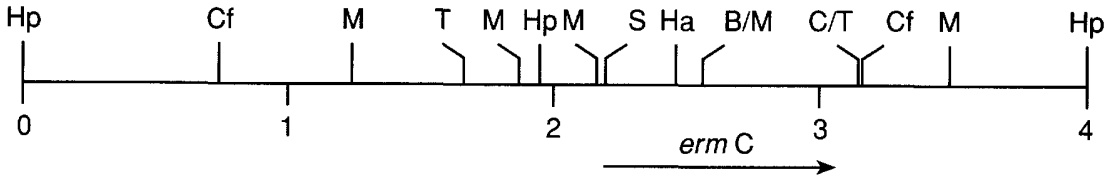

pNE131

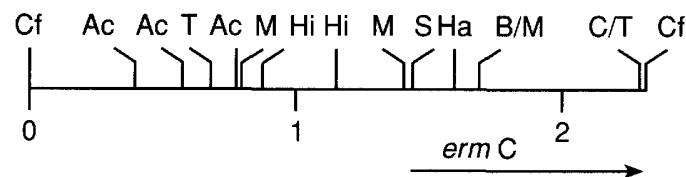

pSES21

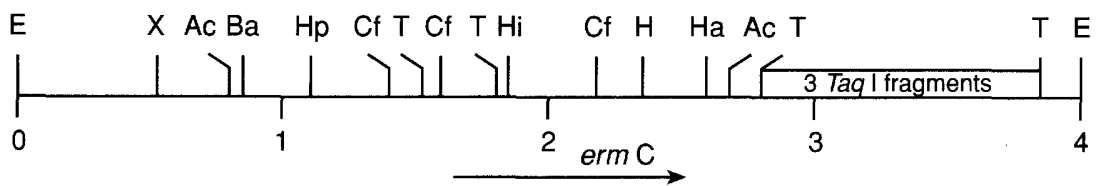

Fig. 1. Comparison of the restriction maps of the ermC-encoding plasmids pE194 from $S$. aureus, pSES6 from $S$. equorum, pNE131 from $S$. epidermidis and pSES21 from $S$. hyicus. Restriction endonuclease cleavage sites are abbreviated as follows: Ac, AccI; B, BclI; Ba, Bam HI; C, ClaI; Cf, CfoI; E, EcoRI; H, HpaI; Ha, HaeIII; Hi, HindIII; Hp, HpaII; M, MboI; Ps, PstI; S, SacI; T, TaqI; X, XbaI. A distance scale in kb is shown below each map; the arrows indicate the extent and the direction of transcription of the erm $\mathrm{C}$ gene.

Localisation of the ermC gene in pSES21 was performed by the marker inactivation strategy. E. coli JM107 transformants of recombinant pBluescript II $\mathrm{SK}+$ which carried the EcoRI-, XbaI-, Bam HI-, HpaII- or Hae III-linearised pSES21 plasmid as an insert grew on nutrient agar containing erythromycin $150 \mathrm{mg} / \mathrm{L}$. However, those with the HindIII-linearised pSES2 1 as insert showed no growth after $24 \mathrm{~h}$ at $37^{\circ} \mathrm{C}$ on that medium. This suggested that the HindIII site was located either within the erm $\mathrm{C}$ structural gene or within its essential regulatory region. Sequence analysis of this HindIII clone showed that the HindIII site was located within an open reading frame for a protein of 244 amino acids (Fig. 2). Among the 36 base-pair substitutions seen within the erm $\mathrm{C}$ reading frame, 18 were involved in changes of the amino-acid sequence. Another five were responsible for the generation of new recognition sites for the enzymes HindIII (position 269, A-C), Taq I (position 233, A$\mathrm{G}$ ) and $C f o \mathrm{I}$ (position 605, A-G), but also for the destruction of the recognition sites for Hae III (position 314, C-G) and $B c l$ I (position 408, G-A). Comparison of this reading frame with the erm $\mathrm{C}$ gene of $\mathrm{pE} 194$ showed $95.1 \%$ homology in the nucleotide sequences and $93.4 \%$ identity in the deduced aminoacid sequences. The structural relationship of the pSES21-encoded ErmC methylase to other adenine methylases of this hybridisation class is shown in Fig. 3a. The cladogram (Fig. 3b) confirmed that the pSES21-encoded adenine methylase differed the most from the ErmC methylases known so far.

\section{Analysis of the ermC translational attenuator and transcriptional terminator}

Plasmid pSES21 conferred combined resistance to 14-, 15- and 16-membered macrolides and also to lincosamides without previous induction by erythromycin. This resistance pattern confirmed that the pSES21encoded ermC gene was expressed constitutively. A comparison of the pSES21-encoded erm C translational attenuator with the corresponding region of $\mathrm{pE} 194$ revealed the presence of 14 base-pair insertions and another 21 base-pair substitutions within the 188-bp region preceding the erm $\mathrm{C}$ structural gene (Fig. 2). Conversion of $\mathrm{C}$ to $\mathrm{T}$ at position 17 deleted the $\mathrm{Sac} \mathrm{I}$ cleavage site while the insertion of an additional $G$ at position 19 and the substitution of $\mathrm{T}$ by $\mathrm{C}$ at position 20 generated a new $C f o$ I cleavage site. Five base-pair insertions were located in the reading frame of the small regulatory peptide with one of them deleting the start codon (ATG-ATTG). No other start codon was found in this region that could functionally replace this deleted start codon. The inverted repeated segments were also affected by base-pair substitutions (Fig. 2). As inducible erm $\mathrm{C}$ gene expression requires the 
c $\downarrow t \quad \downarrow \quad$ ac $\quad \downarrow \downarrow \quad \downarrow \downarrow t \quad$ gg $\downarrow$ a $\quad \downarrow \quad \downarrow \quad \downarrow$ AATTTGACCAGGAGCTTGGCGCTATAAGTTATTTTAAGGTTTATAAGAAGGAGAATTAATAGTATTGGGC
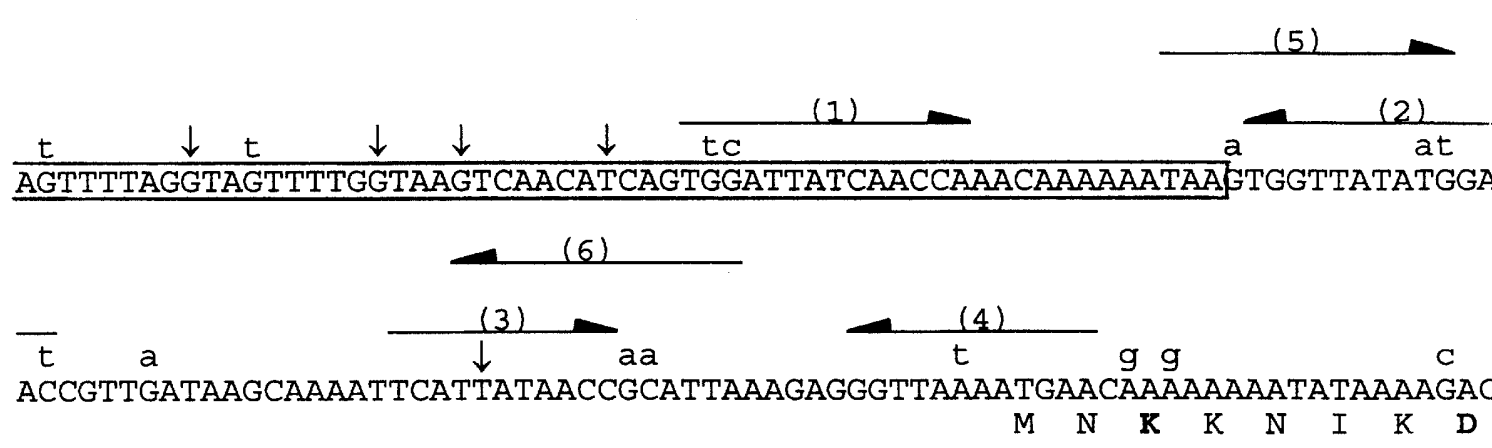

a $\quad a \quad a$

a

AGTCAAAACTTTATTACTTCGAAACGTAATGTAGATAAAATAATGACAAATATAAGCTTAAATGAACATGAT

$\begin{array}{llllllllllllllllllllllll}S & Q & N & F & I & T & S & K & R & N & V & D & K & I & M & T & N & I & S & L & N & E & H & D\end{array}$

C $\quad$ C

a $g$

AATATCTTTGAAATTGGCTCAGGAAAAGGGCATTTTACCCTTGAATTAGTACAAAGGTGTAATTTCGTAACT

$\begin{array}{llllllllllllllllllllllll}N & I & F & E & I & G & S & G & K & G & H & F & T & L & E & L & V & Q & R & C & N & F & V & T\end{array}$

C
GCTATTGAAATAGACCATAAATTATGCAAGACTACAGAAAATAAACTTGTTAATCACGATAATTTTCAAGTT

$\begin{array}{llllllllllllllllllllllllll}A & I & E & I & D & H & K & L & C & K & T & T & E & N & K & L & V & N & H & D & N & F & Q & V\end{array}$

TTAAACAAGGATATATTGCAGTTTAAATTTCCTAAAAACCAATCCTATAAAATATTTGGTAGTATACCTTAC 500

$\begin{array}{llllllllllllllllllllllll}\mathrm{L} & \mathrm{N} & \mathrm{K} & \mathrm{D} & \mathrm{I} & \mathrm{L} & \mathrm{Q} & \mathrm{F} & \mathrm{K} & \mathrm{F} & \mathrm{P} & \mathrm{K} & \mathrm{N} & \mathrm{Q} & \mathrm{S} & \mathrm{Y} & \mathrm{K} & \mathrm{I} & \mathbf{F} & \mathrm{G} & \mathbf{S} & \mathrm{I} & \mathrm{P} & \mathrm{Y}\end{array}$

a $\quad t \quad a \quad a \quad t$

AACATAAGTACGGATATAATACGCAAAGTTGTTTTTGAAAGTATAGCTGATGAGAGTTATTTAATCGTGGAA

$\begin{array}{llllllllllllllllllllllll}N & I & S & T & D & I & I & R & K & V & V & F & E & S & I & A & D & E & S & Y & L & I & V & E\end{array}$

$\begin{array}{llll}a & a & a & a\end{array}$

TACGGGTTTGCTAAAAGGTTATTGAATACAAAGCGCTCATTGGCGTTACTTTTAATGGCAGAAGTTGATATT

$\begin{array}{llllllllllllllllllllllllllllll}Y & G & F & A & K & R & L & L & N & T & K & R & S & L & A & L & L & L & M & A & E & V & D & I\end{array}$

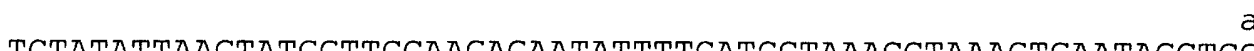

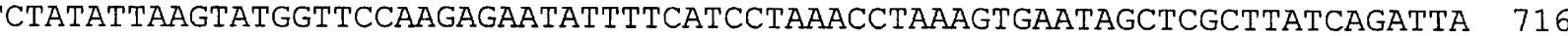
$\begin{array}{llllllllllllllllllllllll}S & I & L & S & M & V & P & R & E & Y & F & H & P & K & P & K & V & N & S & S & L & I & R & I\end{array}$

g ac a

AATAGAAAAAAATCAAGAATATCGTACAAAGATAAACAGAAGTATAATTATTTCGTTATGAAATGGGTTAAC

$\begin{array}{llllllllllllllllllllllll}\mathbf{N} & \mathrm{R} & \mathrm{K} & \mathrm{K} & \mathrm{S} & \mathrm{R} & \mathrm{I} & \mathrm{S} & \mathbf{Y} & \mathrm{K} & \mathrm{D} & \mathrm{K} & \mathrm{Q} & \mathrm{K} & \mathrm{Y} & \mathrm{N} & \mathrm{Y} & \mathrm{F} & \mathrm{V} & \mathrm{M} & \mathrm{K} & \mathrm{W} & \mathrm{V} & \mathrm{N}\end{array}$

788

AAAGAATACAAGAAAATATTTACAAAGAATCAATTTAACAAATCCTTAAAACATGCGGGAATTGACGATTA 8 t

$\begin{array}{lllllllllllllllllllllllll}K & E & Y & K & K & I & F & T & K & N & Q & F & N & K & S & L & K & H & A & G & I & D & D & L\end{array}$

Fig. 2. Nucleotide sequence of the 973-bp erm $\mathrm{C}$ gene region of plasmid pSES21 presented in capital letters. The vertical arrows $(\downarrow)$ indicate base insertions. Lower case letters mark base conversions in comparison to the corresponding sequence of the prototype plasmid $\mathrm{pE} 194$. The former reading frame of the 19 amino-acid peptide is boxed. The amino-acid sequence of the erm $\mathrm{C}$ reading frame is displayed in the single letter code; bold-typed amino acids are exchanged in comparison to pE194. The translational stop codon is marked by an $\left(^{*}\right)$. Inverted repeated segments (1) to (6) in the erm C translational attenuator as well as (7) and (8) which represent the transcriptional terminator are indicated by arrows. 
PT 48

pIM13 :

pSES4a:

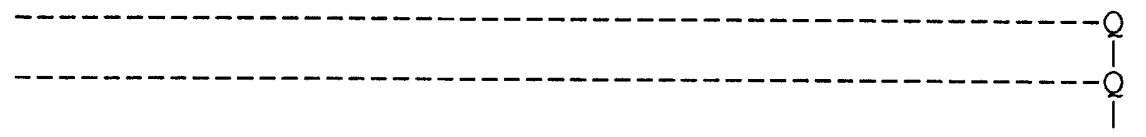

PSES5 :

pE194 :

pNE131:

pSES21:

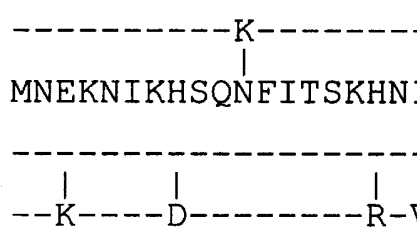

$-50$

- 50

$-50$

- 50

$-50$

$-50$

- 50

PT48 :
pIM13 :

pSES4a:

pSES5 :

pE194 :

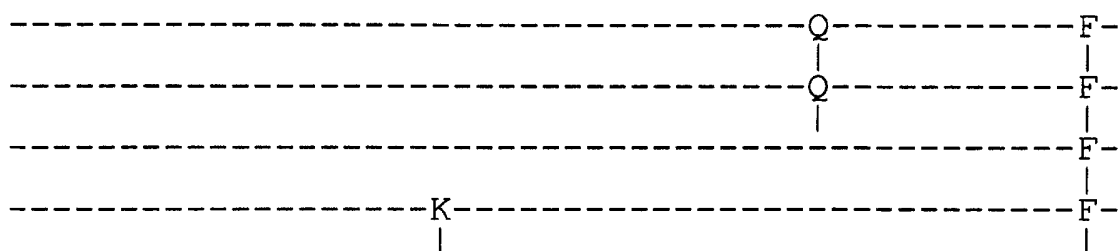

$-100$

$-100$

$-100$

$-100$

PNE131:

pSES21:

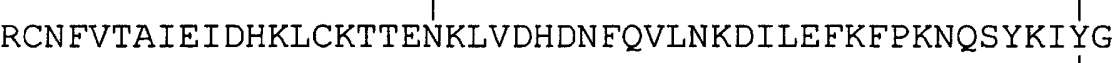

$-100$

$-100$

$-100$

pT48 :
pIM13 :
PSES4a:

pSES5 :

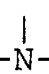

$-\mathrm{F}-$
$-\mathrm{F}-$

PE194: NIPYNISTDIIRKIVFDSIANEIYLIVEYGFAKRLLNTKRSLALLLMAE

pSES21:

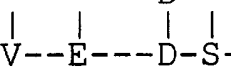

- 150

- 150

$-150$

- 150

- 150

- 150

- 150

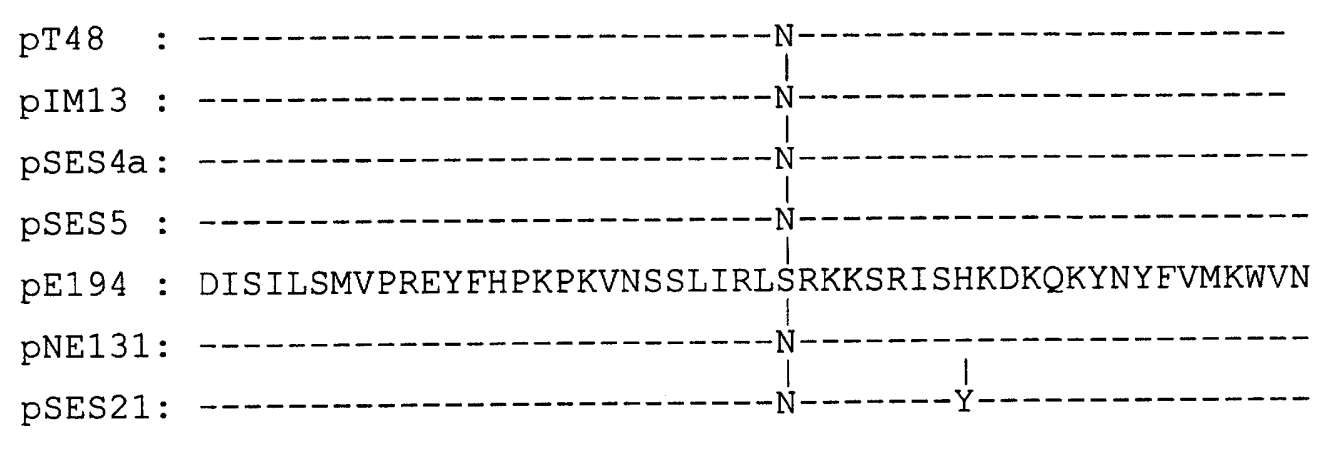

- 200

- 200

- 200

- 200

- 200

- 200

- 200

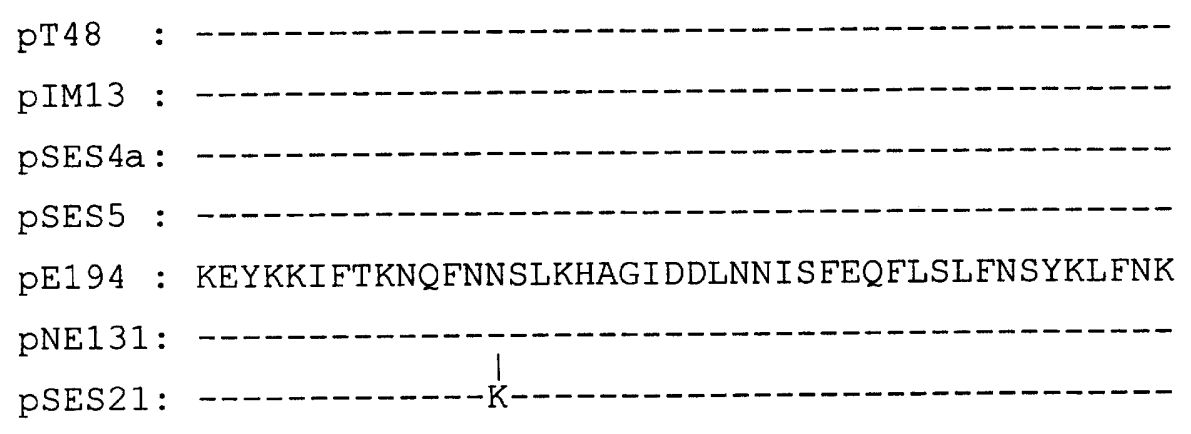

- 244

- 244

- 244

- 244

- 244

- 244

$-244$

Fig. 3. (a) Comparison of the amino-acid sequences of ErmC methylases from staphylococci and bacilli. Dashes (-) indicate the presence of the same amino acid as reported for the ErmC methylase of pE194. The methylases encoded by plasmids pSES6 and pE194 were indistinguishable by their amino-acid sequences (Fig. 3b, see over). 
b Percent amino acid identity
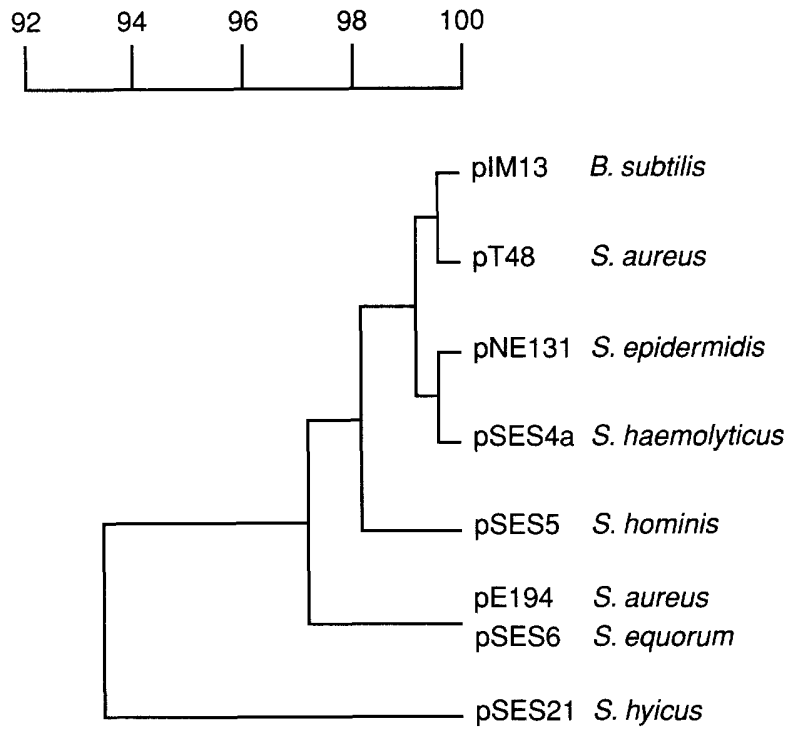

Fig. 3. (b) (contd) Cladogram showing the structural relationships of these ErmC methylases.

formation of different mRNA secondary stuctures by these inverted repeats, base-pair substitutions in the inverted repeats changed the stability of the stem-loop structures. Thus, the free energy of pairing of segments $1: 2$ was decreased from $\Delta G=-13.4 \mathrm{kcal}$ (c. $-56.1 \mathrm{~kJ}) / \mathrm{mol}$ in $\mathrm{pE} 194$ to $\Delta G=-5.0 \mathrm{kcal}(c$. $-20.9 \mathrm{~kJ}) / \mathrm{mol}$ in pSES21, that of pairing of segments $2: 3$ from $\Delta G=-12.4 \mathrm{kcal} \quad(c . \quad-51.9 \mathrm{~kJ}) / \mathrm{mol}$ in pE194 to $\Delta G=-9.4 \mathrm{kcal}($ c. $39.4 \mathrm{~kJ}) / \mathrm{mol}$ in pSES21, and finally that of pairing of segments $3: 4$ from $\Delta G=-12.2 \mathrm{kcal} \quad(51.1 \mathrm{~kJ}) / \mathrm{mol}$ in $\mathrm{pE} 194$ to $\Delta G=-10.8 \mathrm{kcal}(c .45 .2 \mathrm{~kJ}) / \mathrm{mol}$ in $\mathrm{pSES} 21$. The base-pair substitutions also generated a new pair of inverted repeated segments, designated 5:6, which encompassed parts of segments 2 and 3 . The free energy of pairing of segments 5:6 was calculated to be $\Delta G=-11.0 \mathrm{kcal}(c .46 .1 \mathrm{~kJ}) / \mathrm{mol}$. The calculation of the free energies of the different mRNA secondary structures confirmed that there will be a greater tendency for segments $5: 6$ to form the energetically most stable secondary structure, than for segments $1: 2$ or 2:3 to form a stem-loop structure. If segments $5: 6$ pair, there is no partner left for segment 4 to form a secondary stucture. Moreover, the unpaired state of segment 4 will render the ribosome-binding site for the erm $\mathrm{C}$ structural gene which is located within segment 4 accessible to ribosomes and so allow constitutive ErmC synthesis to occur.

The transcriptional terminator, composed of another two inverted repeated sequences 7 and 8 , starts in the translational stop codon of the erm $\mathrm{C}$ structural gene. It also showed several base-pair exchanges which destabilised the secondary structure obtained from pairing of segments $7: 8$ from $\Delta G=-28.4 \mathrm{kcal}$ (c. $118.9 \mathrm{~kJ}) / \mathrm{mol}$ in $\mathrm{pE} 194$ to $\Delta G=-21.4 \mathrm{kcal}$ (c. $89.6 \mathrm{~kJ}) / \mathrm{mol}$ in $\mathrm{pSES} 21$. Moreover, conversion of A to $\mathrm{G}$ at positions 932 and 936 (Fig. 3) destroyed the recognition sequence for the restriction enzyme Cla I.

\section{Discussion}

Antibiotics of the MLS group can be subdivided into two groups: (i) the inducers of erm $\mathrm{C}$ gene expression which include 14- and 15-membered macrolides and (ii) the non-inducers which comprise 16-membered macrolides, lincosamides and streptogramin B antibiotics [17, 18]. Staphylococci that carry inducible erm $\mathrm{C}$ genes are resistant only to inducers. This led to the assumption that inducibly erm $\mathrm{C}$ resistant staphylococci can effectively be treated with non-inducing members of the MLS group of antibiotics. However, such inducibly erm $\mathrm{C}$ resistant strains were found to be able to mutate to constitutive resistance in the presence of non-inducers [35]. First observations of this change of the type of gene expression [36] were made some time before the first erm $\mathrm{C}$ gene was sequenced and the translation attenuation model $[19,37]$ for inducible erm $\mathrm{C}$ gene expression was proposed. Several years later, in-vitro studies of constitutive mutants selected from inducibly erm $\mathrm{C}$ resistant strains on media containing tylosin, clindamycin, spiramycin or pristinamycin revealed structural alterations in the erm $\mathrm{C}$ translational attenuator $[20,23,35,38]$.

Two types of alterations were observed: sequence deletions and sequence duplications. The 59-bp deletion detected by Horinouchi and Weisblum [20] comprised the entire reading frame for the 19 aminoacid peptide including the inverted repeated segment 1. Constitutive mutants selected from clinical specimens also exhibited sequence deletions of varying extent within the translational attenuator $[4,8,10]$. A deletion of $107 \mathrm{bp}$ which removed the reading frame for the small peptide and also the inverted segments 1 , 2 and 3, was found to occur most frequently [10]. Besides these sequence deletions, a direct tandem duplication of $109 \mathrm{bp}$ of the translational attenuator was observed in a constitutive mutant selected in vitro [23]. Other tandem duplications were seen in vivo in epidemiologically unrelated staphylococcal strains. Thus, duplication of a 28-bp fragment which contained parts of the inverted repeats 1 and 2 was detected in plasmid pRJ5 from $S$. aureus [12] while Lodder et al. [9] described the duplication of a 23-bp fragment which included the inverted repeat 4 and the first $5 \mathrm{bp}$ of the erm $\mathrm{C}$ structural gene to be present in plasmid pSES6 from $S$. equorum.

First indications for the in-vitro selection of uninducible/constitutive mutants by point mutation of important positions within the translational attenuator were obtained from analysis of the tyc- 1 mutant of plasmid pE194 [23]. The conversion from A to C 
within the translational start codon of the reading frame for the small peptide deleted this start codon and was considered to be responsible for constitutive erm $\mathrm{C}$ gene expression [23]. The assumption that translation of the small peptide is required for erm $\mathrm{C}$ induction was confirmed by Dubnau [39] who obtained an uninducible mutant by replacing the second codon of the 19 amino-acid peptide by a stop codon. While these mutations were selected randomly under laboratory conditions [23] or introduced artificially [39], data have not been available to confirm the occurrence of similar mutations in vivo. The data obtained from the naturally occurring plasmid pSES21, however, might fill this gap. Multiple basepair exchanges and insertions were detected in the pSES21-encoded translational attenuator, several of which affected structures of importance for the regulation of the erm $\mathrm{C}$ gene. Deletion of the translational start codon for the small regulatory peptide in combination with frame-shift mutations in the reading frame destroyed this regulatory element. As the first nine codons of this small 19 amino-acid peptide are crucial for stalling a ribosome during induction [35, 40, 41], deletion of the reading frame for this small peptide might explain the uninducibility of the pSES21-encoded erm $\mathrm{C}$ gene. However, lack of inducibility does not consequently result in constitutiveness. As long as segments 1:2 and 3:4 form stable mRNA secondary structures and no ribosome is stalled in the region of segment 1 , the erm C-associated ribosomal binding site and the start codon for the erm C methylase gene will be buried within the stemloop structure 3:4 and therefore remain unaccessible to ribosomes. In pSES21, the base-pair substitutions within the inverted repeated segments mainly affected segments 1 and 2 and distinctly decreased the stability of mRNA secondary structures formed by pairing of $1: 2$ as well as $2: 3$. Pairing of the newly generated inverted repeats $5: 6$, which include part of segment 2 and the entire segment 3 , might explain the constitutive type of erm $\mathrm{C}$ gene expression. Pairing of segments 5:6 will lead to the energetically most stable stem-loop structure and well leave segment 4 unpaired. Thus, the ermC-associated ribosome-binding site and the start codon for the erm $\mathrm{C}$ methylase gene will become accessible to ribosomes.

Previous studies have shown that an inducibly erm $\mathrm{C}$ resistant strain is able to mutate to constitutive erm $\mathrm{C}$ gene expression with a high probability [35]. The corresponding mutations were all located in the erm $\mathrm{C}$ translational attenuator and similar if not identical mutations were found under laboratory conditions as well as in vivo. The rapid development of constitutive resistance by sequence deletions or sequence duplications might be explained by an apparent single mutational step [35]. The observation that the corresponding ErmC methylases encoded by plasmids such as pSES6, pSES4a, pNE131 or pIM13 were either identical to that of $\mathrm{pE} 194$ or differed from it by
4, 5 or 6 amino acids confirmed that mutation to constitutive resistance was not accompanied by extensive alterations in the erm $\mathrm{C}$ structural gene, but remained mainly limited to the translational attenuator. Comparison of the deduced amino-acid sequences of the sequenced erm $\mathrm{C}$ genes of staphylococci and bacilli showed that the ErmC methylases are very closely related (Fig. 3a, b), however, with the pSES21encoded ErmC methylase differing the most from all other adenine methylases of this hybridisation class. It is not known how many mutational steps during which time have been necessary to change the pSES21encoded erm $\mathrm{C}$ translational attenuator from an inducible type to its present constitutive type and to account for the 16-amino-acid exchanges within the erm $\mathrm{C}$ methylase gene.

From the clinical point of view, mutation from inducible to constitutive resistance is accompanied by a widening of the spectrum of antibiotics to which resistance is expressed, which means from limited resistance to 14- and 15-membered macrolides in inducibly resistant strains to overall resistance to 14-, 15-, and 16-membered macrolides, lincosamides and streptogramin B antibiotics in constitutively resistant strains. The use of non-inducing MLS antibiotics as growth promoters in livestock might favour the occurrence of mutations to constitutive resistance. A recent study [10] revealed that randomly selected erm C-carrying strains from various domestic animals showed a strong correlation between the type of erm $\mathrm{C}$ gene expression and the previous contact of the animal to non-inducing MLS antibiotics. While none of the animals which carried inducibly erm $\mathrm{C}$ resistant staphylococcal strains had any previous contact with 16-membered macrolides, lincosamides or streptogramins, most of the constitutively erm $\mathrm{C}$ resistant strains were obtained from animals that had received 16membered macrolides as growth promoters or lincosamides for therapeutic purposes. Knowledge of the mutational events that cause a change in the type of erm $\mathrm{C}$ gene expression and of the consequences for the effectiveness of MLS antibiotics to control macrolide-resistant staphylococci demand a careful and judicious use of non-inducing MLS antibiotics. This may include a restriction of the use of 16membered macrolides as growth promoters in livestock.

We thank Irene Greiser de Wilke, Magret Koeller and Regine Neth, Institute for Virology, Hanover School for Veterinary Medicine, Hanover, Germany, for help with sequence analyses. C. L. received a scholarship from the German Academic Exchange Service (DAAD). C. W. is the recipient of a fellowship of the Graduiertenkolleg 'Zell und Molekularbiologie in der Tiermedizin' (GRK 158/2-96) funded by the Deutsche Forschungsgemeinschaft.

\section{References}

1. Lyon BR, Skurray R. Antimicrobial resistance of Staphylococcus aureus: genetic basis. Microbiol Rev 1987; 51: 88-134. 
2. Weisblum, B. Erythromycin resistance by ribosome modification. Antimicrob Agents Chemother 1995; 39: 577-585.

3. Eady EA, Ross JI, Tipper JL, Walters CE, Cove JH, Noble WC. Distribution of genes encoding erythromycin ribosomal methylases and an erythromycin efflux pump in epidemiologically distinct groups of staphylococci. J Antimicrob Chemother 1993; 31: 211-217.

4. Catchpole I, Dyke KGH. A Staphylococcus aureus plasmid that specifies constitutive macrolide-lincosamide-streptogramin $\mathrm{B}$ resistance contains a novel deletion in the erm $\mathrm{C}$ attenuator. FEMS Microbiol Lett 1990; 69: 43-48.

5. Catchpole I, Thomas C, Davies A, Dyke KGH. The nucleotide sequence of Staphylococcus aureus plasmid pT48 conferring inducible macrolide-lincosamide-streptogramin B resistance and comparison with similar plasmids expressing constitutive resistance. $J$ Gen Microbiol 1988; 134: 697-709.

6. Greene RT, Schwarz S. Small antibiotic resistance plasmids in Staphylococcus intermedius. Zentralbl Bakteriol 1992; 276: 380-389.

7. Horinouchi S, Weisblum B. Nucleotide sequence and functional map of $\mathrm{pE} 194$, a plasmid that specifies inducible resistance to macrolide, lincosamide, and streptogramin type B antibiotics. J Bacteriol 1982; 150: 804-814.

8. Lampson BC, Parisi JT. Nucleotide sequence of the constitutive macrolide-lincosamide-streptogramin B resistance plasmid pNE131 from Staphylococcus epidermidis and homologies with Staphylococcus aureus plasmids pE194 and pSN2. J Bacteriol 1986; 167: 888-892.

9. Lodder G, Schwarz S, Gregory P, Dyke K. Tandem duplication in erm $\mathrm{C}$ translational attenuator of the macrolide-lincosamidestreptogramin B resistance plasmid pSES6 from Staphylococcus equorum. Antimicrob Agents Chemother 1996; 40: 215-217.

10. Lodder G, Schwarz S, Gregory P, Dyke KGH. Molecular analysis of plasmids from animal staphylococci mediating inducible or constitutive resistance to macrolide-lincosamide antibiotics. Abstracts of the 8th International Symposium on Staphylococci and Staphylococcal Infections, Aix-Les-Bains, France, 23-26 June 1996: P-191, 236.

11. Lodder G, Werckenthin C, Schwarz S, Dyke KGH. Comparative analysis of the erm $\mathrm{C}$ adenine methylase genes encoded by the staphylococcal plasmids pSES4a, pSES5 and pSES6. EMBL Nucleotide Sequence Database, Cambridge, UK 1996: access. no. Y09001, Y09002.

12. Oliveira SS, Murphy E, Gamon MR, Bastos MCF. pRJ5, a naturally occurring Staphylococcus aureus plasmid expressing constitutive macrolide-lincosamide-streptogramin B resistance contains a tandem duplication in the leader region of the erm $\mathrm{C}$ gene. J Gen Microbiol 1993; 139: 1461-1467.

13. Schwarz S, Blobel H. Isolation of a plasmid from "canine" Staphylococcus epidermidis mediating constitutive resistance to macrolides and lincosamides. Comp Immunol Microbiol Infect Dis 1990; 13: 209-216.

14. Schwarz S, Wegener H, Blobel H. Plasmid-encoded resistance to macrolides and lincosamides in Staphylococcus hyicus. $J$ Appl Bacteriol 1990; 69: 845-849.

15. Schwarz S, Cardoso M, Grölz-Krug S, Blobel H. Common antibiotic resistance plasmids in Staphylococcus aureus and Staphylococcus epidermidis from human and canine infections. Zentralbl Bakteriol 1990; 273: 369-377.

16. Weisblum B, Graham MY, Gryczan T, Dubnau D. Plasmid copy number control: isolation and characterization of highcopy-number mutants of plasmid pE194. J Bacteriol 1979; 137: $635-643$.

17. Allen NE. Macrolide resistance in Staphylococcus aureus: inducers of macrolide resistance. Antimicrob Agents Chemother 1977; 11: 669-674.

18. Leclercq $R$, Courvalin $P$. Bacterial resistance to macrolide, lincosamide, and streptogramin antibiotics by target modification. Antimicrob Agents Chemother 1991; 35: 1267-1272.

19. Dubnau D. Translational attenuation: the regulation of bacterial resistance to the macrolide-lincosamide-streptogramin B antibiotics. CRC Crit Rev Biochem 1984; 16: 103-132.

20. Horinouchi S, Weisblum B. The control region for erythromycin resistance: free energy changes related to induction and mutation to constitutive expression. Mol Gen Genet 1981; 182 341-348.

21. Weisblum B. Inducible resistance to macrolides, lincosamides and streptogramin type B antibiotics: the resistance phenotype its biological diversity, and structural elements that regulate expression - a review. J Antimicrob Chemother 1985; 16 Suppl A: 63-90.

22. Monod M, Denoya C, Dubnau D. Sequence and properties of pIM13, a macrolide-lincosamide-streptogramin B resistance plasmid from Bacillus subtilis. J Bacteriol 1986; 167: 138147.

23. Gryczan TJ, Grandi G, Hahn J, Grandi R, Dubnau D. Conformational alteration of mRNA structure and the posttranscriptional regulation of erythromycin-induced drug resistance. Nucleic Acids Res 1980; 8: 6081-6097.

24. Woods GL, Washington JA. Antibacterial susceptibility tests: dilution and disk diffusion methods. In: Murray PR, Baron EJ, Pfaller MA. Tenover FC, Yolken RH (eds) Manual of clinical microbiology. 6th edn. Washington, DC, American Society for Microbiology. 1995: 1327-1341.

25. Schwarz S, Cardoso M, Blobel H. Plasmid-mediated chloramphenicol resistance in Staphylococcus hyicus. $J$ Gen Microbiol 1989; 135: 3329-3336.

26. Chang $\mathrm{S}$, Cohen SN. High frequency transformation of Bacillus subtilis protoplasts by plasmid DNA. Mol Gen Genet 1979; 168: $111-115$.

27. Schwarz S, Noble WC. Tetracycline resistance genes in staphylococci from the skin of pigs. J Appl Bacteriol 1994; 76: $320-326$.

28. Werckenthin C, Schwarz S, Dyke K. Macrolide-lincosamidestreptogramin B resistance in Staphylococcus lentus results from the intergration of part of a transposon into a smal plasmid. Antimicrob Agents Chemother 1996; 40: 2224-2225.

29. Murphy E, Huwyler L, do Carmo de Freire, Bastos M. Transposon Tn554: complete nucleotide sequence and isolation of transposition-defective and antibiotic-sensitive mutants. EMBO J 1985; 4: 3357-3365.

30. Dagert $M$, Ehrlich SD. Prolonged incubation in calcium chloride improves the competence of Escherichia coli cells Gene 1979; 6: 23-28.

31. Sambrook J, Fritsch EF, Maniatis, T. Molecular cloning: a laboratory manual, 2nd edn. Cold Spring Harbor, NY, Cold Spring Harbor Laboratory Press. 1989.

32. Sanger F, Nicklen S, Coulson AR. DNA sequencing with chain-terminating inhibitors. Proc Natl Acad Sci USA 1977; 74: $5463-5467$.

33. Tinoco I, Borer PN, Dengler B et al. Improved estimation of secondary structure in ribonucleic acids. Nature New Biol 1973; 246: 40-41.

34. Dice LR. Measures of the amount of ecologic association between species. Ecology 1945; 26: 297-302.

35. Weisblum B. Insights into erythromycin action from studies of its activity as inducer of resistance. Antimicrob Agents Chemother 1995; 39: 797-805.

36. Watanakunakorn C. Clindamycin therapy of Staphylococcus aureus endocarditis. Clinical relapse and development of resistance to clindamycin, lincomycin and erythromycin. $A m$ $J$ Med 1976; 60: 419-425.

37. Horinouchi S, Weisblum B. Posttranscriptional modification of mRNA conformation: mechanism that regulates erythromycininduced resistance. Proc Natl Acad Sci USA 1980 77: 7079 7083.

38. Hahn J, Grandi G, Gryczan TJ, Dubnau D. Translational attenuation of ermC: a deletion analysis. Mol Gen Genet 1982; 186: $204-216$

39. Dubnau D. Induction of erm C requires translation of the leader peptide. EMBO J 1985; 4: 533-537.

40. Mayford M, Weisblum B. erm C leader peptide. Amino acid sequence critical for induction by translational attenuation. $J$ Mol Biol 1989; 206: 69-79.

41. Mayford M, Weisblum B. The erm C leader peptide: amino acid alterations leading to differential efficiency of induction by macrolide-lincosamide-streptogramin B antibiotics. $J \mathrm{Bac}$ teriol 1990; 172: 3772-3779. 